Original Research

\title{
The Effectiveness of Spiritual Emotional Breathing Towards Respiratory Function and Immune Response of Tuberculosis Patients
}

\author{
Kusnanto Kusnanto, Joni Haryanto, Tintin Sukartini, Elida Ulfiana and Made Mahaguna Putra
}

Faculty of Nursing Universitas Airlangga, Surabaya, Indonesia

\begin{abstract}
Introduction: Tuberculosis is one cause of infectious death worldwide. In relation to the healing of pulmonary tuberculosis in Indonesia, there are still certain areas where the cure rate is still low. This study aims to identify the effect of spiritual emotional breathing (SEB) on the quality of respiratory function and the modulation of immune response in tuberculosis patients.

Methods: The study used a quasi-experimental design with two groups of prepost-test design. The population was 34 patients with tuberculosis in East Perak's primary health care. The independent variable was SEB (spiritual emotional breathing). The dependent variables were peak expiratory flow rate (PEFR), pulse, oxygen saturation, breath frequency, breath sound, stiffness complaints, human IL2, human cortisol, IgG.

Results: The results showed that there was a significant difference in PEFR, pulse, oxygen saturation, respiratory rate, respiratory sound, stiffness, human IL-2, human cortisol, IgG.

Conclusion: SEB can improve the quality of respiratory function and the modulation of immune response in tuberculosis patients. The emotional spiritual approach is part of the science of energy psychology that aims to turn the negative energy in a person into positive energy that can help the healing process. This therapy is performed as a complementary therapy for TB patients to improve their quality of life and the control of symptoms.
\end{abstract}

Cite this as: Kusnanto, K., Haryanto, J., Sukartini, T., Ulfiana, E., \& Putra, M. (2018). The Effectiveness of Spiritual Emotional Breathing towards Respiratory Function and Immune Response of Tuberculosis Patients. Jurnal Ners, 13(1). 93-97. doi:http://dx.doi.org/10.20473/in.v13i1.8373

\section{INTRODUCTION}

Tuberculosis is one cause of infectious death worldwide (WHO, 2008). The healing of pulmonary tuberculosis in Indonesia is still low in certain areas. The disease is chronic, and can affect the quality of life of the sufferer. Patients living with tuberculosis (TB) experience the significant disruption of their social life and are exposed to both stigma and discrimination. Pulmonary tuberculosis poses serious problems, relating to the concept of quality of life consisting of the aspects of physical, psychological, social, and environmental health (Kusnanto, Pradanie and Karima, 2016). TB is a common cause of death in people with HIV. The duration of the treatment for tuberculosis is prolonged, and is at least 6 months for drug-prone TB and 18-24 months for multi-drug resistant TB (MDR-TB), which does not respond to the two most effective anti-TB drugs, isoniazid and rifampicin.

\section{ARTICLE HISTORY}

Received: May 19, 2018

Accepted: June 8, 2018

\section{KEYWORDS}

immune; spiritual emotional breathing; respiratory function; tuberculosis

\section{CONTACT}

Kusnanto Kusnanto $\triangle$ kusnanto@fkp.unair.ac.id $\equiv$ Faculty of Nursing Universitas Airlangga, Surabaya, Indonesia

Long-term treatment, adverse drug reactions during the TB treatment, stigma and financial burden contribute to poor treatment and treatment outcomes. In addition, ensuring patient adherence to treatment through a direct facility for observation therapy (DOT) competes with patient-centered services, adding to the involved finances. The costs come from out-of-pocket and there are indirect costs associated with the treatment. This is even though anti-TB drugs are given free of charge in most countries. Rapid healing of the symptoms of TB at the onset of treatment also contributes to improper patient care (i.e. people who are lost to follow-up) as competing interests are prioritised. Poor treatment obedience and the negligence of follow-up increases the morbidity, mortality, and risk of developing drug resistance, and can lead to prolonged TB transmission (Hoorn et al., 2016).

EFT (emotional freedom technique) is one of the therapeutic groups that is referred to as 
psychological energy (Church et al., 2012). EFT is a mild and non-invasive form of emotional acupressure by using an acupuncture meridian called "acupuncture without needles". Tapping the meridian point on the upper body releases the energy blockage ("energy therapy") and reinforces the patient's cognitive change for them to take full responsibility for their own health and well-being (Bougea et al., 2013). In addition, there is a repetition of self-acceptance statements, which are suggested to contribute to cognitive restructuring, a well-known psychotherapeutic technique, in which individuals identify and correct negative thoughts (Patterson, 2016). The effectiveness of SEFT (Spiritual Emotional Freedom Technique) lies in the merging of Spiritual Power with Energy Psychology. Spiritual Power contains the five main principles of sincerity, confidence, gratitude, and patience. Energy Psychology is a set of principles and techniques utilising the body's energy system to improve the state of the person's mind, emotions, and behaviour. Chemical imbalances and energy disturbances in the human body can cause emotional distress, including depression. SEFT intervention in the body's energy system can change the chemical conditions in the brain (neurotransmitter), which can further change the emotional condition of a person, including the condition of depression. In addition, SEFT is effective, easy, fast, cheap, the effect can be permanent and there are no side effects. It is universal and empowers the individual (so they are not dependent on the therapist), and it can be explained scientifically (Astuti, Yosep and Susanti, 2015).

Spiritual Emotional Breathing (SEB) is a therapy using the Spiritual Emotion Freedom Technique (SEFT), which is then followed by breathing exercises. The emotional spiritual approach is a part of the science of energy psychology that aims to turn the negative energy in a person into positive energy that can help the healing process. (Zainudin, 2006). This approach is done using the body's energy system to cure patients, as in acupuncture or acupressure, but with simple techniques. The process consists of three stages, namely the set-up, the tune-in and the tapping. The set-up aims to ensure the proper flow of bodily energy. The tune-in aims to direct our mind to the pain and to feel the pain that we experience. The tapping is a light tap on certain points that neutralises emotional and pain disorders (Zainudin, 2006).

In improving the immunological factor, our study shows that EFT can increase lymphocyte proliferation. There is the assumption that greater proliferation is associated with more effectiveness when it comes to an immune response (Aggarwal and Gurney, 2002). Furthermore, EFT can increase IL-17 in the peripheral blood of chemically and pulmonary injured veterans. IL-17 is a proinflammatory cytokine produced by activated memory $\mathrm{T}$ cells, that has a key role in the host's defence against microbial infections such as mycobacterium tuberculosis (Jovanovic et al., 1998). It has a key role in the initiation and maintenance of inflammatory responses (Zhang et al., 2012). The cells that produce IL-17 have an important role in controlling both immune and inflammatory reactions (Lutgendorf and Costanzo, 2003). Many studies have shown that stress can affect the function and number of immune cells (Carlson et al., 2004), the production of many cytokines, like IL-4, IFN- $\gamma, \quad L-10$ and the reduction of lymphocyte proliferation (Lengacher et al., 2013). The main objectives of this study were to analyse changes in breath frequency, PEFR, oxygen saturation, breath sound, congested, cortisol, IL-2, and IG. The second goal was to explain the relationship between the variables.

\section{MATERIALS AND METHODS}

This research was a quasi-experimental research study with a non-randomised (purposive sampling) Control Group Pre-test and Post-test Design. The sample in this study was made up of 34 people with the inclusion criteria of 1) positive acid-resistant bacteria TB patient, 2) productive age and 3) got standard therapy from primary health care. The exclusion criteria in this study were that they were TB patients with complications. The independent variable in this research was SEB (Spiritual Emotional Breathing), while the dependent variables in this research were cortisol, IL-2, IgM, PEFR, Oxygen Saturation, Respiratory Rate (RR), Pulse, Complaints, and breath sound.

First, we selected patients who met the inclusion criteria from each group in the first part of the study, and we enrolled those patients into the second part of the study. The patients were divided into 2 groups of 17 patients, and they were trained using an original program. The patients were also instructed to practice daily exercise at home. Before the exercises, the patient was trained beforehand and given guidance. Compliance with daily exercise was assessed weekly using an observation sheet filled in with the patients at home. The assessments were repeated 12 weeks after the beginning of the SEB program. SEB involves focusing on the situation identified as causing distress and tapping on specific meridian points of the body with breathing retraining, which consisted of relaxation, pursed lip breathing, and slow-deep breathing with training occurring in both the supine and sitting positions using the classic method of Miller (Miller, 1954), with slight modifications. Intervention was performed once a day. The control group was given treatment according to the standard of care in the primary health care centre. The respondent's sampling was done by the purposive sampling method. The sample was taken by a nurse in primary health care. The samples were then analysed at the Institute of Tropical Diseases.

The place of study was East Perak primary health care, January - February 2015. The instrument used 
was a peak flow meter to measure PEFR. Pulse oximetry was used to measure SaO2. Salivary Cortisol ELISA was used for the cortisol examination. The lowest detectable level of cortisol that can be distinguished from the Zero Standard is 0.537 $\mathrm{mg} / \mathrm{mL}$ or $0.0537 \mu \mathrm{g} / \mathrm{dL}$ at the $95 \%$ confidence limit. Legend Max Human IL-2 Elisa used for the human IL2 examination, and the minimum detectable concentration of IL-2 is $4 \mathrm{pg} / \mathrm{mL}$. Gen Way Mycobacterium IgG was used for the examination of IgG, with a clinical sensitivity of $100 \%$. The salivary cortisol and IgG concentration were determined using an enzyme-linked immunosorbent assay. The collected data was analyzed using a paired t-test. The instrument used in the research was made in Japan. The analysis was conducted using SPSS with Paired t-test $(\mathrm{p} \leq 0.05)$. The ethical considerations were met, as the participants signed an informed consent form. Moreover, their privacy, confidentiality, and voluntary participation was ensured. The study was approved by the Health Research Ethics Committee Faculty of Nursing Universitas Airlangga (No. 57KEPK).

\section{RESULTS}

Based on Table 1, the number of the intervention and control group respondents was 17 people. The number of male respondents in the intervention group was $76.47 \%$ and in the control, it was $52.94 \%$. The female respondents in the intervention group were $23.52 \%$ and $47.05 \%$ respectively. The mean age of the respondent intervention group was 41.17 years and in the control group, it was 47.76 years.

The mean human value of IL- 2 in the intervention group before intervention was 30.95, and after intervention, it was 45.52 . The mean values of the human cortisol group before and after intervention were 156.64 and 137.60 respectively. The mean IgG groups of before and after intervention were respectively 10.75 and 14.58 .

Table 1 Demographic and Baseline Characteristics

\begin{tabular}{|c|c|c|c|}
\hline \multicolumn{2}{|c|}{ Characteristics } & Intervention & Control \\
\hline \multicolumn{4}{|l|}{ Gender } \\
\hline \multicolumn{2}{|l|}{ Male } & $13(76.47 \%)$ & $9(52.94 \%)$ \\
\hline \multicolumn{2}{|c|}{ Female } & $4(23.52 \%)$ & $8(47.05 \%)$ \\
\hline \multicolumn{2}{|c|}{ Age (year) } & 41.17 & 47.76 \\
\hline \multicolumn{4}{|c|}{ Breathing Pattern } \\
\hline \multirow[t]{2}{*}{ Pre test } & Dyspnea & $12(70.59 \%)$ & $\begin{array}{c}10 \\
(58.82 \%)\end{array}$ \\
\hline & Normal & $5(29.41 \%)$ & $7(41.18 \%)$ \\
\hline \multirow[t]{2}{*}{ Post test } & Dyspnea & $0(00.00 \%)$ & $\begin{array}{c}12 \\
(70.59 \%)\end{array}$ \\
\hline & Normal & $17(100.00 \%)$ & $5(29.41 \%)$ \\
\hline \multicolumn{4}{|c|}{ Breathing Sound } \\
\hline \multirow[t]{2}{*}{ Pre test } & Vesicular & $11(64.71 \%)$ & $\begin{array}{c}13 \\
(76.47 \%)\end{array}$ \\
\hline & $\begin{array}{l}\text { Not } \\
\text { Vesicular }\end{array}$ & $6(35.29 \%)$ & $4(23.53)$ \\
\hline \multirow[t]{2}{*}{ Post test } & Vesicular & $17(100.00 \%)$ & $15(88.24)$ \\
\hline & $\begin{array}{l}\text { Not } \\
\text { vesicular }\end{array}$ & $0(00.00 \%)$ & $2(11.76)$ \\
\hline
\end{tabular}

\section{DISCUSSION}

Based on Table 2, there was an SEB effect on human IL-2, human cortisol, and Ig G. In improving immunologic factors, (Babamahmoodi et al., 2015) shows that EFT may increase lymphocyte proliferation. It is assumed that greater proliferation is associated with a more effective immune response. Furthermore, EFT may increase IL-17 in chemically-injured veteran's peripheral blood. IL-17 is a pro-inflammatory cytokine produced by activated memory $\mathrm{T}$ cells and has a key role in host defense against microbial infections, such as Mycobacterium tuberculosis. It has a key role in the initiation and maintenance of the inflammatory response. The cells that produce IL-17 have an important role in controlling immune and inflammatory reactions. Many studies have shown that stress can affect the function and number of immune cells, the production of many cytokines, such as IL-4, IFN- $\gamma$, L-10 and the reduction of lymphocyte proliferation. Furthermore, stress management intervention can reduce the immunosuppressive effects of stressors. There are many papers on the effect of other stress management techniques such as mindfulness-based stress reduction (MBSR) on immunological factors, but no studies of EFT and immunity. In Table 2, it can be seen that the decrease of the cortisol in the control group occurred because the respondent was able to manage the stress. Cortisol can be associated with emotions, and can cause long-term physiological effects (Trial, 2012).

The exercise of the respiratory muscles and chest muscles can increase lung capacity. The results showed a strong correlation between the diffusion capacity of vital pulmonary capacity. Exercise in the form of breathing exercises such as deep breathing exercises can be done by healthy people or lung problem sufferers in order to increase lung volume and capacity. The lung function status is identified by the ability of gas exchange to provide oxygen to the alveoli, so it is mutually sustainable to determine the oxygen saturation value. Doing deep breathing exercises can help in the process of oxygenation so that the saturation levels can persist within the normal range (Priyanto, 2010).

Deep breathing will reduce sympathetic reactions to improve respiratory patterns and decrease inspiratory and expiratory muscle contractions (Yadav, Singh and Singh, 2009). Shortness of breath may decrease as the breathing pattern changes from the rapid rate, which is under the control of the involuntary respiratory centre of the brain stem, and the pattern thus becomes more controlled. (Nusdwinuringtya, 2000). Our study had some limitations. To elucidate the effectiveness of SEB on non-TBC patients, a prospective, randomised, controlled study is necessary. Another limitation of our study was the difficulty of proving statistical equivalence. In general, to prove statistical equivalence, there needs to be a large sample size. 
Table 2 Statistical Analysis

\begin{tabular}{lcccccc}
\hline \multirow{2}{*}{ Variable } & \multicolumn{2}{c}{ Intervention (Mean) } & P value & \multicolumn{2}{c}{ Control (Mean) } & P value \\
\cline { 2 - 7 } & Before & After & & Before & After & \\
\hline Human IL-2 & 30.95 & 45.52 & 0.00 & 32.75 & 44.06 & 0.01 \\
Human Cortisol & 156.64 & 137.60 & 0.01 & 131.02 & 43.52 & 0.79 \\
IgG & 10.75 & 14.58 & 0.00 & 8.29 & 3.48 & 0.10 \\
PEFR & 221.18 & 254.71 & 0.00 & 236.47 & 242.94 & 0.28 \\
Heart rate & 87.29 & 79.64 & 0.00 & 87.41 & 91.29 & 0.00 \\
Saturation O2 & 98.29 & 95.70 & 0.00 & 87.41 & 95.94 & 0.00 \\
Respiratory Rate & 22.70 & 17.94 & 0.00 & 21.29 & 23.11 & 0.03 \\
\hline
\end{tabular}

\section{CONCLUSION}

Spiritual Emotional Breathing (SEB) can decrease human IL-2, human cortisol, and Ig G. Using an emotional spiritual approach is a part of the science of psychological energy that is capable of improving the immune system. This therapy is performed as a complementary therapy for TB patients to improve their quality of life and the control of their symptoms. It is used as a therapy that supports major treatment therapies.

\section{REFERENCES}

Aggarwal, S. and Gurney, A. L. (2002) 'IL-17: prototype member of an emerging cytokine family', Journal of leukocyte biology, 71(1), pp. 1$8 . \quad$ Available at: http://eutils.ncbi.nlm.nih.gov/entrez/eutils/elin k.fcgi?dbfrom=pubmed\&id=11781375\&retmode =ref\&cmd=prlinks\%5Cnpapers $3: / /$ publication $/ \mathrm{u}$ uid/C6B73D07-6483-4B7C-B182-

BAE723F8A26A. (Accessed: January 1, 2017).

Ando, M. et al. (1999) 'A study of the long-term effectiveness of an outpatient pulmonary rehabilitation program', Nihon Kokyuki Gakkai zasshi = the journal of the Japanese Respiratory Society, 37(9), pp. 680-687.

Astuti, R., Yosep, I. and Susanti, R. D. (2015) 'Effect of Intervention Spiritual Emotional Freedom Technique toward Decrease the Level of Depression Housewife with HIV', Jurnal Keperawatan Padjadjaran, 3(April 2015), pp. 4456.

Babamahmoodi, A. et al. (2015) 'Emotional Freedom Technique (EFT) Effects on Psychoimmunological Factors of Chemically Pulmonary Injured Veterans', Journal Allergy Asthma Immunology, 14(February), pp. 37-47.

Bougea, A. M. et al. (2013) 'Effect Of The Emotional Freedom Technique On Perceived Stress, Quality Of Life, And Cortisol Salivary Levels Intension Type Headache Sufferers: A Randomized Controlled Trial', JSCH. Elsevier Inc., 9(2), pp. 9199. doi: 10.1016/j.explore.2012.12.005.

Carlson, L. E. et al. (2004) 'Mindfulness-based stress reduction in relation to quality of life, mood, symptoms of stress and levels of cortisol, dehydroepiandrosterone sulfate (DHEAS) and melatonin in breast and prostate cancer outpatients', Psychoneuroendocrinology, 29(4), pp. 448-474. doi: 10.1016/S03064530(03)00054-4.

Church, D. et al. (2012) 'Single-Session Reduction of the Intensity of Traumatic Memories in Abused Adolescents after EFT : A Randomized Controlled Pilot Study', Traumatology, 18(3). doi: 10.1177/1534765611426788.

Clark, C. J., Cochrane, L. and Mackay, E. (1996) 'Low intensity peripheral muscle conditioning improves exercise tolerance and breathlessness in COPD', European Respiratory Journal, 9(12), pp. 2590-2596.

doi: 10.1183/09031936.96.09122590.

Hoorn, R. Van et al. (2016) 'The Effects of PsychoEmotional and Socio- Economic Support for Tuberculosis Patients on Treatment Adherence and Treatment Outcomes - A Systematic Review and Meta- Analysis', pp. 1-27. doi: 10.1371/journal.pone.0154095.

Jovanovic, D. V et al. (1998) 'IL-17 stimulates the production and expression of proinflammatory cytokines, IL-beta and TNF-alpha, by human macrophages', Journal of immunology, 160(7), pp. 3513-21.

Kusnanto, K., Pradanie, R. and Karima, I. A. (2016) 'Spiritual Emotional Freedom Technique ( SEFT) terhadap Kualitas Hidup Penderita Tuberkulosis Paru Spiritual Emotional Freedom Technique ( SEFT ) and the Quality of Life of People Living with Lung Tuberculosis', Jurnal Keperawatan Padjadjaran, 4, pp. 213-224. Available at: http://ikp.fkep.unpad.ac.id/index.php/jkp/articl e/view/284/134. (Accessed: January 1, 2017).

Lengacher, C. A. et al. (2013) 'Lymphocyte Recovery After Breast Cancer Treatment and MindfulnessBased Stress Reduction (MBSR) Therapy', Biological Research for Nursing, 15(1), pp. 37-47. doi: $10.1177 / 1099800411419245$.

Lutgendorf, S. K. and Costanzo, E. S. (2003) 'Psychoneuroimmunology and health psychology: An integrative model', Brain, Behavior, and Immunity, pp. 225-232. doi: 10.1016/S08891591(03)00033-3.

Miller, W. F. (1954) 'A physiologic evaluation of the effects of diaphragmatic breathing training in patients with chronic pulmonary emphysema', The American Journal of Medicine, 17(4), pp. 471477. doi: 10.1016/0002-9343(54)90122-9.

Nusdwinuringtya, N. (2000) Efek latihan otot-otot pernafasan pada penyakit paru obstruksi kronis di instalasi rehabilitasi medik RSUPN Dr. 
Ciptomangunkusumo Jakarta. Universitas Indonesia.

Patterson, S. L. (2016) 'The Effect Of Emotional Freedom Technique On Stress And Anxiety In Nursing Students: A Pilot Study', Nurse Education Today. Elsevier B.V. doi: 10.1016/j.nedt.2016.02.003.

Priyanto (2010) Pengaruh deep breathing exercise terhadap fungsi ventilasi oksigen paru pada klien post ventilasi mekanik. Universitas Airlangga.

Trial, A. R. C. (2012) 'The Effect of Emotional Freedom Techniques on Stress Biochemistry', 200(10),

pp.

891-896.

doi:
10.1097/NMD.0b013e31826b9fc1.

WHO (2008) Global Burden of Disease 2004 Update. WHO.

Yadav, A., Singh, S. and Singh, K. . (2009) ' 'Role of pranayama breathing exercise in rehabilitation of coronary artery disease patient-a pilot study', Indian Journal of Traditional Knowledge, 8(3).

Zhang, L. et al. (2012) 'Effects and mechanism of arsenic trioxide on reversing the asthma pathologies including Th17-IL-17 axis in a mouse model', Iranian Journal of Allergy, Asthma and Immunology, 11(2), pp. 133-145. doi: 011.02/ijaai.133145. 